\title{
Aula de Física no Ensino Superior: uma análise da participação dos alunos sob a ótica interacional
}

\author{
Valesca Brasil Irala \\ Liziane Padilha Mena
}

Rafael Kobata Kimura

\section{Resumo}

Este trabalho visa analisar a interação em uma aula de Física Geral I, em um curso de graduação presencial de Física, em uma universidade pública federal brasileira. Evidenciam-se as tomadas de turnos pelos alunos, as falas iniciadas por eles e a sequência de falas identificadas nessa aula (com grande incidência de participação discente). Entre os resultados, percebeu-se que o professor teve papel incentivador para a participação dos alunos, através de um conjunto de estratégias situadas, verbais e não-verbais. Por fim, salientase que pesquisas dessa natureza se tornam relevantes para compreender situações corriqueiras de sala de aula, visando a tomada de decisões sobre diferentes aspectos, desde os mais sutis da interação face a face até aos relacionados à dimensão curricular, de forma mais ampla.

Palavras-chave: interação em sala de aula; ensino superior; construção do conhecimento. 
Physics classroom in Higher Education: an analysis of the participation of students from an interactionist perspective

Valesca Brasil Irala

Liziane Padilha Mena

Rafael Kobata Kimura

\section{Abstract}

This work aims at analyzing the interaction in a General Physics I class, in a Physics undergraduate course, in a brasilian federal public university. The turn taking by the students, the speeches initiated by them, and the sequence of speeches identified in this class (with a high incidence of student participation) are evidenced. Among the results, it was observed that the professor had an incentive rol for student participation, through a set of strategies, verbal and nonverbal. Finally, it should be pointed ou that researchs of this nature becomes relevant to understanding everyday classroom situations, aiming at making decisions on different aspects, from the subtlest of face-to-face interaction to those related to the curricular dimension, more broadly.

Keywords: interaction in the classroom; Higher Education; construction of knowledge. 


\section{Introdução}

Pela linguagem, especialmente a verbal, é que desenvolvemos a maioria das interações ao longo da vida. Desde crianças, aprendemos crenças, valores, formas de nos colocarmos no mundo em relação às culturas e aos grupos (BAIÃO, 2009). Pela linguagem, também são revelados diferentes mecanismos de pertencimento a um grupo. Nesse sentido, a sala de aula é um espaço privilegiado para observar um tipo específico de interação, aquela que visa promover a construção do conhecimento, em cada contexto institucional situado de ensino-aprendizagem. Ainda, o senso de pertencimento (TINTO, 2015), que se desenvolve em outras instâncias institucionais, para além da sala de aula, precisa ser positivamente reforçado nesse espaço, em benefício dos avanços acadêmicos esperados na formação dos estudantes. Assim, compreendemos que a linguagem, na sala de aula, funciona tanto como mediadora quanto como reguladora (GABBIANI, 2000), tendo o docente o papel crucial de articulador nesse cenário.

Nesta pesquisa, desenvolvida no âmbito do projeto "Aprendizagens ativas e colaborativas: análise da percepção docente, do engajamento discente, da autorregulação e do processo avaliativo", no interior do Grupo de Pesquisa Aprendizagens, Metodologias e Avaliação (GAMA/registrado no Diretório de Grupos de Pesquisa do CNPq), não nos limitamos a compreender a sala de aula apenas como um espaço para ensinar e para a aprender, pois ela é mais do que isso, é também uma situação social, a qual, conforme descreve Cajal (2009, p. 125), é "aquela em que os atores encontram-se face a face, eles sofrem, em suas ações [e] influência uns dos outros".

Além disso, a autora ressalta que há um trabalho social contínuo, constituído por princípios organizacionais implícitos ou explícitos, sendo o conjunto, cada um a seu modo, capaz de refletir características encontradas unicamente nesse espaço, marcado tanto por dinamismo quanto por complexidade, por relações possivelmente mais simétricas (como, em tese, é a relação aluno-aluno) etambém assimétricas (como, também em tese, é a relação professor-aluno). Aqui, colocamos sob rasura o pressuposto da simetria aluno-aluno, especialmente ao nos determos ao Ensino Superior, quando, não raras vezes, em modelos curriculares que aderem ao formato disciplinar (e não modular ou por projetos, por exemplo), um aluno poderá ter como único interlocutor validado o professor, e não os colegas. Essa situação pode ocorrer por não haver, nesse espaço, a noção de "turma", como na Educação Básica, onde é favorecido o senso de pertencimento e, em decorrência disso, a espontaneidade das interações entre os pares (tal situação pode ser identificada quando alunos cursam disciplinas fora do seu semestre indicado, por motivo de reprovação anterior ou outras razões).

Com base no exposto, este artigo, a partir de uma aula de Física Geral I, em uma instituição pública de ensino Superior, busca analisar a interação no contexto de uma aula do componente de graduação Física Geral I, integrante da matriz curricular de um curso 
presencial de formação de professores de Física. Uma compreensão situada, à luz dos referenciais teóricos e metodológicos adotados, pode vir a contribuir: (i) no campo empírico, para a tomada de decisões no que diz respeito à produção dos materiais didáticos utilizados nesse componente, à própria organização dos espaços físicos destinados para as aulas, etc., e, também; (ii) no campo teórico, para promover um processo reflexivo informado a docentes dessa área do conhecimento (e de áreas afins) sobre as situações de aula que costumam ser corriqueiras, ainda que, em geral, não problematizadas em níveis mais profundos, para além dos vivenciados em seus contextos imediatos.

Nas seções seguintes, apresentamos um apanhado crítico em relação aos modelos que têm pautado a produção do conhecimento científico, bem como seu impacto nos percursos formativos no ensino de Ciências Exatas, como é o caso da disciplina de Física por nós analisada na pesquisa. Além disso, faremos uma breve discussão teórica para elucidar a noção de participação, à luz de uma abordagem híbrida (sociológica, dos estudos da linguagem e educacional). Na sequência, contextualizaremos o cenário investigado e a metodologia de pesquisa empregada e, por fim, apresentaremos e discutiremos os dados gerados em sala de aula.

\section{Perspectivas e possibilidades para pensar a construção do conhecimento}

No âmbito da produção de conhecimento científico, há indicações de uma conturbada transição entre um paradigma conhecido como dominante ou moderno, pautado pelo cientificismo, onde apenas o conhecimento científico é válido e reconhecido, e um paradigma emergente ou pós-moderno, em que a ciência e o senso comum se unem em prol de uma nova visão do mundo (SANTOS, 2008; KUHN, 1998). Dessa maneira, o primeiro se caracteriza pela priorização das leis da chamada ciência moderna, bem como dos aspectos empíricos dos fenômenos naturais que encontram respaldo em tais leis, de forma que se constituam "um tipo de causa formal que privilegia o como se faz das coisas em detrimento do qual o agente ou o qual fim das coisas" (SANTOS, p. 30, 2008).

O paradigma emergente, por sua vez, é vislumbrado por Santos (2008) através de um conjunto de teses que apresentam suas possíveis características para o conhecimento, sendo elas: todo conhecimento científico-natural é científico-social, todo conhecimento é local e total, todo conhecimento é autoconhecimento e todo conhecimento científico visa se constituir em senso comum. Tais teses apresentam justificativas e novas perspectivas para a produção de conhecimento científico atreladas às concepções do senso comum.

Santos (2008) sinaliza a transição do paradigma dominante para o emergente de forma conflituosa, marcada por uma gama de condições teóricas e sociais. Desse modo, o autor destaca: [...] que a identificação dos limites, insuficiências estruturais do paradigma científico moderno é o resultado do grande avanço no conhecimento que ele propiciou. $\mathrm{O}$ 
aprofundamento do conhecimento permitiu ver a fragilidade dos pilares em que se funda (SANTOS, 2008, p. 41).

Tais paradigmas, mesmo em crise há décadas, bem como as concepções que eles abarcam, influenciam sobremaneira as formas de pensar a Educação, em todos os níveis, bem como as abordagens adotadas pelos professores em sala de aula, de forma que emerge a busca por práticas educativas que sejam adequadas para tratar temas de estudo naturalizados pelo fazer científico, sob uma nova roupagem. Tal condição se dá porque, apesar dos questionamentos e das mudanças de paradigmas serem há bastante tempo anunciadas, há ainda uma sobrevalorização do saber acumulado historicamente, no âmbito da cultura (e da ciência como um produto cultural), presente de forma inquestionável nos currículos escolares e universitários, em um processo complexo na busca de quaisquer rupturas.

Nesse contexto de transição entre paradigmas, torna-se possível a discussão sobre a consequente oposição ferrenha ao que Saviani (1999) nomeia como pedagogia tradicional, na qual:

A escola surge como um antídoto à ignorância, logo, um instrumento para equacionar o problema da marginalidade. Seu papel é difundir a instrução, transmitir os conhecimentos acumulados pela humanidade e sistematizados logicamente. O mestre-escola será o artífice dessa grande obra. A escola se organiza, pois, como uma agência centrada no professor, o qual transmite, segundo uma gradação lógica, o acervo cultural aos alunos. A estes cabe assimilar os conhecimentos que lhes são transmitidos (SAVIANI, 1999, p. 18).

A crise desse modelo surge com o insucesso de seus métodos, somada à crise do paradigma dominante, uma vez que não se pautava nem no acesso universal e nem mesmo muitos daqueles que estavam aparentemente inseridos podiam alcançar bons resultados em termos de aprendizagem. Nesse cenário, começou a se delinear um ensino de base interacionista, pautado em uma perspectiva holística, visando gerar conhecimentos a partir da co-construção entre os alunos e os aspectos sociais e científicos. Nele, toma-se o processo de aprendizagem como aspecto principal e não mais meramente os resultados, como no modelo ainda atualmente predominante em salas de aula de todos os níveis de ensino (CHAHUÁNJIMÉNEZ, 2009).

Entretanto, Pimenta (1996), ao citar estudos relacionados à formação inicial de professores, sinaliza que a construção de currículos com conteúdos e atividades de estágio distantes da realidade educacional das escolas não abarca as questões próprias da prática social de educar, contribuindo pouco para a construção de uma nova identidade docente, mais alinhada aos tempos e sujeitos da contemporaneidade. Também Pernambuco (1993) colabora nessa linha, ao afirmar que:

[...] a dinâmica básica desencadeada em sala de aula deve permitir uma riqueza de trocas e desafios, que funcionam como motivação e oportunidade 
para que transcendam, de fato, o seu universo imediato e possam adquirir criticamente novas formas de compreendê-lo e atuar sobre ele (PERNAMBUCO, 1993, p. 21).

Nessa perspectiva, na construção de caminhos na busca pela colaboração para o exercício da atividade docente, é necessário ter em mente o papel dos cursos de formação de professores, no Brasil chamados de "licenciaturas", para o desenvolvimento de conhecimentos e habilidades, atitudes e valores que permitam aos alunos a construção contínua de seus saberes-fazeres, com base nas necessidades e desafios que se colocam a partir do ensino como uma prática social (PIMENTA, 1996).

Em aulas de Física, ainda hoje, mesmo no Ensino Superior, perdura uma perspectiva tradicional (MOREIRA, 2018, p. 74), com um modelo focado no professor e "na memorização de fórmulas a serem aplicadas na resolução de problemas conhecidos”. Segundo Lee (2006), nessa mesma linha, muito do discurso matemático com o qual os alunos têm contato é referente ao estilo matemático convencional, ressaltando que os professores devem auxiliar os alunos no entrosamento com as questões matemáticas dentro e fora da sala de aula, de forma a se envolverem plenamente nas convenções da área, tão presentes e necessárias também para o seu desenvolvimento nas aulas de Física.

Nesse sentido, entram em cena as discussões matemáticas, sobre as quais Rodrigues, Menezes \& Ponte (2018), por meio de um estudo de caso com dois professores que integravam um grupo colaborativo, perceberam que os docentes estruturavam a discussão matemática nos seguintes momentos: apresentação; comparação, avaliação e filtragem; e conclusão. A partir disso, praticam ações de ensino conjuntas, que beneficiam a apresentação, justificação e argumentação de diversas estratégias de resolução por parte dos alunos. Pesquisas como a dos autores permitem evidenciar a importância para o desenvolvimento de um olhar detalhado para os processos educativos situados e os modelos de participação discente esperados, assim como buscamos realizar nesta pesquisa.

Vários fatores são responsáveis pela forte permanência de métodos tradicionais de ensino na área de Ciências Exatas. Ataíde e Silva (2011) ressaltam, entre os fatores, que a visão de que a formação inicial é a única etapa de formação docente dificulta a renovação das metodologias adotadas na área. Dessa forma, em geral, aulas de Física e de áreas afins costumam ser pautadas na sistematização de conteúdos por parte do professor e resolução de exercícios, características que, por vezes, aproximam-nas do que Piletti (2004) define como posição dogmática assumida pelo professor em aulas expositivas, na qual a mensagem transmitida não pode ser (ou não é) contestada, devendo ser aceita sem objeções e repetida sempre que solicitado, sem muita mobilidade ou margem para interpretações dissonantes dos alunos. De alguma forma, há nessa concepção uma visão ingênua, que vê a linguagem de forma transparente e inequívoca: em geral, se o aluno não entende, são tomadas, em geral, duas 
posições: ou se repete da mesma maneira ou se segue adiante na explanação, partindo de um ponto não compreendido, como se na sequência pudesse ser supostamente "alcançado".

Em contraponto a essa concepção, o mesmo autor também apresenta a posição de diálogo que o professor pode assumir durante as aulas expositivas, destacando que a mensagem apresentada é um meio pelo qual a participação dos alunos pode ser desencadeada, de forma a abrir espaços de discussão, pesquisa e contestação sempre que houver necessidade. Para tanto, torna-se necessário que o professor atente às novas perspectivas no âmbito do ensino, desde as situações mais sutis que possa vivenciar em sala de aula, criando, assim, um ambiente educativo capaz de gerar senso de pertencimento (TINTO, 2015) e, consequentemente, condição para que os alunos assumam novos papéis e sejam menos passivos na relação com o objeto de ensino e no seu processo formativo mais amplo.

Dessa forma, percebe-se a necessidade de haver práticas inovadoras partindo de professores que formam professores (MORENO \& CÓLON, 2004) na área de Ciências Exatas, relatadas por Silva e Villani (2009) e Rodrigues, Menezes e Ponte (2018). Os novos posicionamentos dos professores e as consequentes inovações enquadram-se na perspectiva de identidade líquida, tal como é concebida pelo sociólogo Zigmund Bauman (2005). Para o autor, não há uma identidade única possível para cada participante de um contexto social. Não existe, em sala de aula, apenas alunos e professor/a. Assim, através de uma analogia com a montagem de um quebra-cabeça, em que não se sabe previamente a imagem que deve ser formada ao completá-lo, Bauman afirma que se inicia esta construção:

[...] Por meio de uma série de peças já obtidas ou que pareçam valer a pena, então se tenta agrupá-las e reagrupá-las para montar imagens (quantas?) agradáveis. Você está experimentando com o que tem. [...] A construção da identidade, [...], é guiada pela lógica da racionalidade do objetivo (descobrir o quão atraentes são os objetivos que podem ser atingidos com os meios que se possui). (BAUMAN, 2005, p. 55).

Na construção de tais identidades, podemos adotar, de forma produtiva, os conceitos de linha e de face, muito presentes em uma análise de natureza interacional. Para entender o conceito de linha, devemos compreendê-lo como um padrão de eventos verbais e não verbais com os quais uma pessoa se expressa sobre determinada situação, bem como sua avaliação sobre os demais envolvidos, incluindo ela mesma. Já o conceito de face diz respeito ao valor social positivo que uma pessoa de fato reivindica para si, a partir da linha que os demais participantes pressupõem que ela assumiu durante um contato (GOFFMAN, 2011). Com isso, a manutenção da face, em geral, é uma condição da interação e inclui objetivos comuns entre os participantes; entre eles, resolver problemas e realizar tarefas, os quais, conforme Goffman (2011), são perseguidos de forma consistente com a manutenção da face. 
Além disso, é necessário trazer à tona a noção de contexto enunciada por Erickson e Shultz (2013), os quais destacam a complexidade dos contextos de uma situação, para além do ambiente físico em que se encontram os participantes da interação ou das pessoas nela envolvidas, mas sim o que elas estão fazendo de instante em instante e por onde e quando elas fazem o que fazem. Ressalta-se aqui a dinâmica implicada na noção de "instante em instante", pois um aluno pode estar, por exemplo, altamente engajado em uma atividade de construção do conhecimento e, no momento seguinte, ao se deparar com uma dificuldade, abandoná-la antes de conclui-la, por apresentar traços de medo ao fracasso (GIL FLORES; DE BESA GUTIÉRREZ, GARZÓN UMERENKOVA, 2020).

O contexto de uma sala de aula requer que os participantes da situação de interação assumam papéis que lhes são atribuídos, o de professor e de aluno, no entanto, tanto os direitos como as obrigações são passíveis de reajustes e reconfigurações, que recebem o nome de estruturas de participação (ERICKSON \& SHULTZ, 2013). Por exemplo, a estrutura de participação em uma aula de natureza meramente expositiva requer do aluno a atribuição de ouvir o professor simplesmente, mas em uma aula em que se espera a construção conjunta do conhecimento, o papel do aluno deve ser radicalmente modificado em comparação ao primeiro modelo e ele precisa assumir um papel eminentemente ativo para que a aprendizagem seja efetiva. Ainda, em uma mesma aula, os papéis podem se alternar ou se reinventar, de forma a conformar uma autoconfiguração altamente situada.

Nesse segundo caso, pode-se dizer que as construções das identidades são líquidas e intermediadas pelos aspectos de linha e face assumidos pelos atores sociais, considerando as mudanças metodológicas mais amplas e as decisões locais em que estão inseridas as interações na Educação Superior. Situamos a perspectiva assumida pelo docente do componente de Física Geral I aqui analisado nesse segundo modelo. Entendemos que, em quaisquer cursos de graduação, mas em especial em cursos de formação de professores, o protagonismo do aluno é uma peça-chave para seu desenvolvimento como futuro profissional. Em contrapartida, esse protagonismo também pode favorecer a integração dos alunos entre si, em perspectivas colaborativas de aprendizagem (SALVAT, 2008), a despeito de todo o território de competitividade e individualismo que muitas vezes possa haver no modus operandi dos sujeitos envolvidos.

Na seção seguinte, apresentaremos um detalhamento sobre o contexto de sala de aula escolhido para este trabalho, bem como os eixos metodológicos sobre os quais nos pautamos para a realização da análise.

\section{Contextualizando o cenário e a metodologia}

A criação de um curso de Física - Licenciatura, em uma universidade federal no extremo sul do Brasil, pautou-se nas dificuldades de suprir a demanda por professores que 
atuem nessa disciplina na região em que a instituição se insere. O Projeto Pedagógico de Curso (PPC) ressalta que a formação oferecida é voltada a um perfil de "físico-educador, focalizada no desenvolvimento de conhecimentos teórico-práticos, valorizando a pluralidade dos saberes, de modo a responder as necessidades contemporâneas da sociedade” (PPC, 2019, p. 19).

O componente curricular "Física Geral I" faz parte do eixo básico da matriz curricular do curso, com carga horária de 90 horas/aula, trazendo, entre os conteúdos previstos, os seguintes: movimento em uma, duas e três dimensões, leis de Newton, trabalho e energia, conservação de energia, sistemas de partículas e conservação de momento, colisões, cinemática e dinâmica das rotações e equilíbrio. Entre os objetivos do componente estão qualificar o graduando na compreensão de fenômenos físicos e na solução de problemas em Física Básica relacionados aos movimentos de translação, rotação e equilíbrio de corpos rígidos na Mecânica Newtoniana.

Especificamente no contexto deste trabalho, o componente curricular estava dividido em três módulos, com durações variáveis cada um deles em termos do número de semanas, com os conteúdos programáticos sendo trabalhados em aulas expositivo-dialogadas (dentre as quais estava a aula objeto deste estudo), aulas de exercícios e atividades complementares, como, por exemplo, a construção de catapultas. No quadro a seguir (Quadro 1), apresentaremos o cronograma de aulas do módulo II, por nele estarem inseridas as duas aulas mencionadas na análise deste artigo.

Quadro 1 - Cronograma do módulo II de Física Geral I

\begin{tabular}{|c|c|c|}
\hline Aula & Data & Atividade Prevista \\
\hline \multicolumn{3}{|r|}{ Módulo II } \\
\hline 16 & $17 / 09$ & Força e Movimento \\
\hline 17 & $19 / 09$ & Força e Movimento - Exercícios \\
\hline 18 & $20 / 09$ & Feriado Estadual \\
\hline 19 & $24 / 09$ & Atrito e Resistência \\
\hline 20 & $26 / 09$ & Atrito e Resistência do Ar - Exercícios \\
\hline 21 & $27 / 09$ & Construção de Catapultas - Prática $\leftarrow$ \\
\hline 22 & $01 / 10$ & Energia I $\leftarrow$ \\
\hline 23 & $03 / 10$ & Energia I - Exercícios \\
\hline 24 & $04 / 10$ & Energia II \\
\hline 25 & $08 / 10$ & Energia II - Exercícios \\
\hline 26 & $10 / 10$ & Finalização dos trabalhos de recuperação \\
\hline 27 & $11 / 10$ & Finalização dos trabalhos de recuperação \\
\hline 28 & $15 / 10$ & Exercícios conceituais \\
\hline 29 & $17 / 10$ & Exercícios de Revisão II \\
\hline 30 & $18 / 10$ & Avaliação 2 \\
\hline
\end{tabular}

Fonte: Os autores 
A aula descrita no artigo foi ministrada no dia 1 de outubro e dizia respeito ao tópico "Energia", tendo como gatilho para as discussões em aula as catapultas feitas com materiais de baixo custo previamente construídas pelos estudantes (Figura 1).

Figura 1 - Construção de catapultas

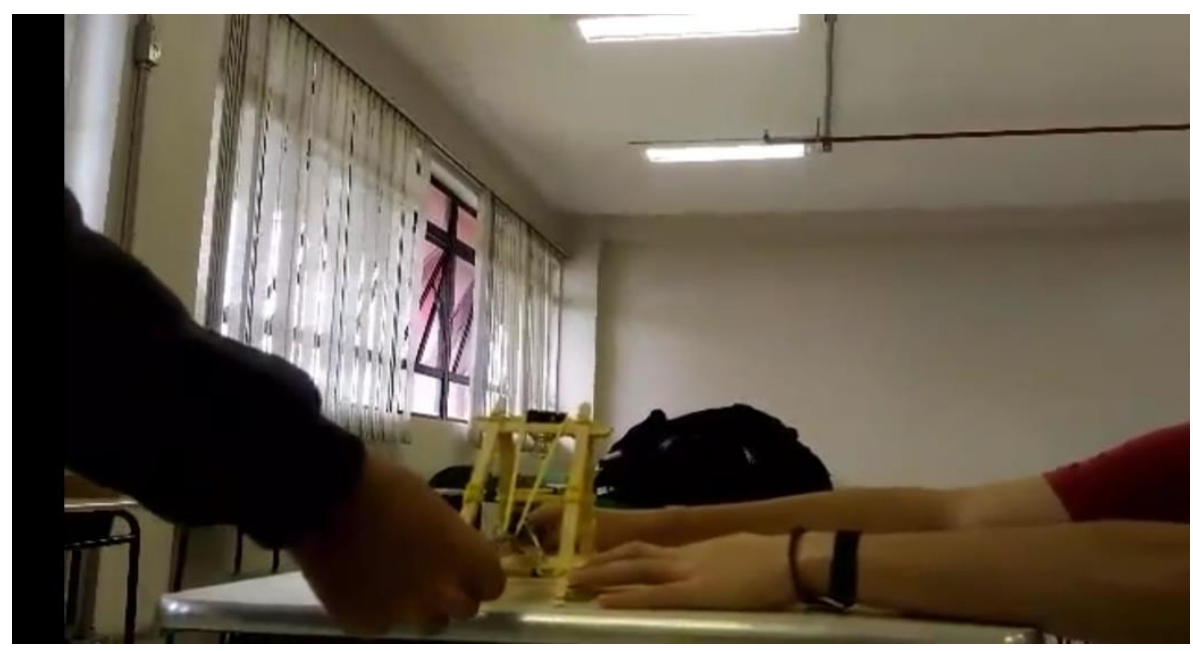

Fonte: Os autores

Com relação aos participantes, pode-se dizer que eram os remanescentes de uma turma inicialmente composta por 20 alunos matriculados. Os seis estudantes presentes na aula objeto ( $22^{\mathrm{a}}$ aula) concluíram o semestre letivo foco desta análise. Foram-lhes atribuídos nomes fictícios, a fim de preservar suas identidades (de acordo ao que lhes foi exposto no Termo de Consentimento Livre e Esclarecido por eles assinado). Segue abaixo um breve histórico dos estudantes no que diz respeito ao componente curricular em questão, os quais ajudam a contextualizar o cenário analisado:

Marcela: estava cursando a componente curricular pela quarta vez. Na aula objeto, mantevese propositalmente distante, segundo ela, para "não embaralhar as ideias", pois faria uma prova substitutiva do mesmo componente curricular na aula seguinte. Não esteve presente na aula de construção de catapultas. Ao final do semestre, foi aprovada.

Vânia: estava cursando o componente curricular pela quarta vez. Em geral, mantinha-se sempre próxima a Marcela. Ao final, foi aprovada.

Diego: estava cursando o componente curricular pela segunda vez. Teve baixa frequência durante o semestre, alegando estar com dificuldades em conciliar o trabalho e os estudos (o curso em questão é diurno). Não estava na aula de construção de catapultas. Ao final, foi reprovado por frequência e por nota.

Luís: estava cursando o componente curricular pela segunda vez. Foi um dos mais ativos na construção das catapultas. Ao final, foi aprovado.

Marcos: estava cursando o componente curricular pela segunda vez. Em geral, mantinha-se próximo a Luís. Ao final, foi aprovado. 
Everton: estava cursando o componente curricular pela sexta vez. Teve pouca participação ativa nas aulas, com muitas faltas e chegando atrasado na maioria das vezes em que comparecia. Não participou da aula de construção de catapultas. Ao final, foi reprovado por frequência e por nota.

Para fins de situar o leitor no contexto da interação, traçou-se um mapa da sala de aula, identificando cada participante e a pesquisadora (Figura 2). O professor, em geral, circulava em frente dos alunos, entre o quadro e os slides projetados.

Figura 2 - Organização espacial da aula foco da observação

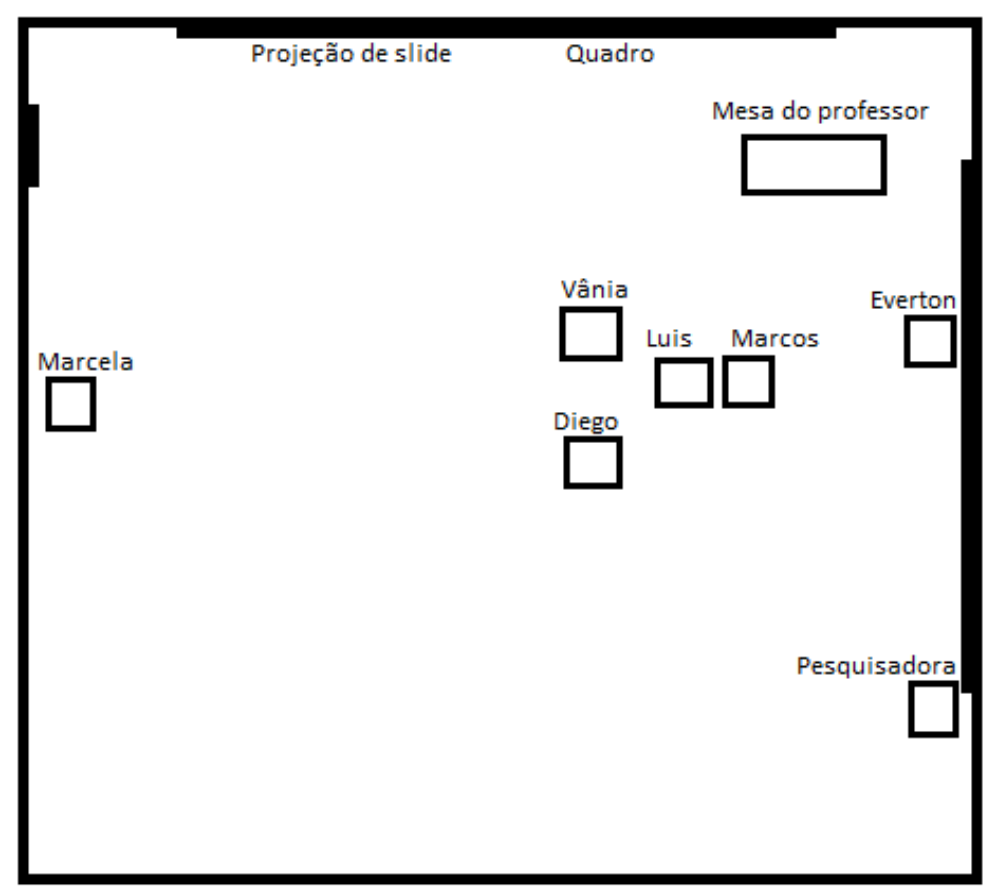

Fonte: Os autores

O vídeo da aula observada, com 87 minutos e 37 segundos, foi assistido seguindo os estágios descritos por Erickson e Shultz (2013) para a análise de interação. Com isso, lançouse mão da triangulação dos dados (BORTONI-RICARDO, 2008), compostos pela transcrição das situações da aula gravada em vídeo e pelas notas de campo em que estavam presentes seis alunos, o professor e uma pesquisadora (na condição de observadora não-participante). Para a construção do presente artigo, também foram utilizados diversos registros fornecidos pelo docente, tais como um questionário inicial de reconhecimento dos alunos, no qual o docente costuma identificar tanto o estilo de aprendizagem de cada um, como seu perfil diante de possíveis dúvidas. Também, se o aluno prefere que o professor lhe pergunte diretamente ou mesmo se se sente constrangido diante de uma pergunta direta. Frente a essas informações, o professor tem o cuidado de respeitar as preferências de cada estudante, identificando, na lista de presença da turma, tais preferências e adotando-as em seus procedimentos durante a condução de cada aula. 
Dessarte, no primeiro estágio, assistiu-se à gravação por inteiro, sem pausas, paralelamente à tomada de notas sobre os aspectos gerais, os quais funcionaram como um índice. Já no segundo estágio, realizou-se o levantamento de situações semelhantes ao longo da gravação, selecionando um tipo de situação para realizar o recorte da análise. No terceiro estágio, identificaram-se as seções de transcrição ou de articulação entre as partes fundamentais da situação, observando as diferenças na estrutura de participação no contexto dessas articulações. Nesse estágio, foi possível assistir a um mesmo trecho mais de uma vez, a fim de perceber e tomar nota sobre as mudanças ocorridas durante a articulação e buscando atentar a um único aspecto do comportamento comunicativo por vez. A partir disso, no quarto estágio, observaram-se as estruturas de participação dos segmentos selecionados, caracterizando-as em linhas gerais e mapeando os aspectos fundamentais da participação. Com os trechos selecionados, realizou-se a transcrição dos recortes, alicerçando-se nas convenções de transcrição utilizadas por Baião (2009), por entendê-las como as que melhor atendiam aos interesses teóricos desta pesquisa (LODER, 2008). Na seção seguinte, apresentamos os resultados e as discussões pertinentes.

\section{Resultados e Discussões}

Os resultados deste estudo mostram um paradigma de mudanças em curso nas aulas de Ciências Exatas no Ensino Superior, de modo que, a partir da observação de uma aula de Física Geral I, percebeu-se que a participação dos alunos, bem como o incentivo docente para que ela ocorra, possa resultar em um encaminhamento conjunto que gera a real construção de conhecimentos, ultrapassando a sua mera memorização. Com isso, Cajal (2001, p. 129) ressalta que "a cultura local de uma sala de aula a distingue de outra sala, mesmo apresentando ambas aparentes similaridades”.

Dessa forma, aqui, a participação, direcionada ao professor, ocorre de duas maneiras: os alunos tomam o turno de fala ou iniciam a fala. Os turnos de fala são caracterizados por Cajal (2001) por meio da sequencialidade de uma conversa, na qual fala um falante por vez, havendo, assim, alternância de falantes na mesma medida em que há alternância de turnos. Podendo, ainda, serem caracterizados através do silêncio e de recursos não verbais, o que permite, em uma dada situação, que, mesmo sem verbalização, um determinado falante tenha o domínio do turno (em sala de aula, de forma geral, ele tacitamente reconhecido como pertencente ao professor). A mesma autora, a partir dos estudos seminais da área da análise interacional, ressalta que é possível o falante que está com a palavra escolher quem irá assumir o turno ou um falante se auto-selecionar para tomar o turno, como geralmente ocorre quando é efetuada uma pausa.

Segundo Recuero (2012, p. 66), "os turnos representam os modos mais básicos de organização de uma conversação" e, ainda, são entendidos como um sistema, que implica em 
"direitos e deveres" e "expectativas", embora sejam, em geral, transgredidos (e até corrigidos, como, por exemplo, quando alguém pede desculpa por haver falado ao mesmo tempo que outro interlocutor, ou seja, havendo sobreposições de fala), o que denota um alto grau de flexibilidade para o desenvolvimento da interação (KEBRAT-ORECHIONI, 2006, p. 43). Em sala de aula, em um contexto dito mais tradicional, a compreensão em relação a essa organização e à distribuição dos turnos de fala geralmente prevê a predominância de turnos por parte do professor e, também, que esses turnos sejam por ele distribuídos aos alunos (com um olhar direcionado a determinado aluno ou mesmo nomeando-o) e não que os alunos tomem o turno sem a permissão explícita ou implícita do docente. Além disso, nesse modelo mais tradicional, sobreposições de fala não "deveriam” ocorrer, de acordo às regras tácitas conhecidas pelos participantes de forma geral.

Dito isso, apresentamos a situação a seguir como uma ruptura dessa expectativa presente de forma evidente em um modelo mais tradicional de ensino. Nesse contexto, percebe-se, nesta primeira situação escolhida para análise, a ocorrência da tomada de turnos pelos alunos e em diversos momentos durante a aula, como no exemplo da situação 1 (S1).

\section{Situação 1:}

1 Professor (6:56 após o início da gravação): Uma catapulta tipo este aqui ((aponta no slide, que trazemos na Figura 3)) ele libera, né, a partir daqui. Chegou nesse ponto aqui tem uma ((fala não compreendida)) então esse projétil ele sai ((gesticula com as mãos, imitando um trajeto do projétil ao ser lançado)) <tá $>$. E a minha pergunta é como você calcular o ângulo $\uparrow$ que ele tá sendo lançado, o Marcos colocou um ângulo complementar aqui ó ((indica o no desenho do slide))

2 Vânia: eu acho que é daquela (baixinha) ali

3 Professor: Dessa a[qui?] ((indica apontando no slide e olha para Vânia))

4 Vânia: [é]...por que é a partir da velocidade não é?

5 Professor: é a veloci[dade]

6 Vânia: [tá] aí não é:: não é aquela... aquele ângulo ali? [no caso...]-

7 Professor: [esse ângulo aqui?]

8 Vânia: não $\uparrow$, do outro de cá.

9 ((O professor indica outro ponto no desenho do slide))

10 Vânia: é, (de cima aí)

11 Professor: aqui a zero graus?

12 Vânia: Não professor <em cima>

13 Professor: aqui? ((indica outro ponto no slide))

14 Vânia: Nã:o professor (.) na caixinha $\uparrow$

15 Professor: então, uma caixinha aqui e uma caixinha aqui, de qual delas cê tá falando? ((usa as duas mãos para sinalizar pontos no slide))

16 Vânia: dessa daí...da de baixo

17 Professor: dessa aqui?

18 Vânia: [é]-

19 Professor: < [tá, qual o ângulo?]>

20 Vânia: -[esse] ângulo tá:... que ela: solta outra, não é (fala não compreendida).

ISSN 2526-2882 
Figura 3 - Slide discutido na Situação 1

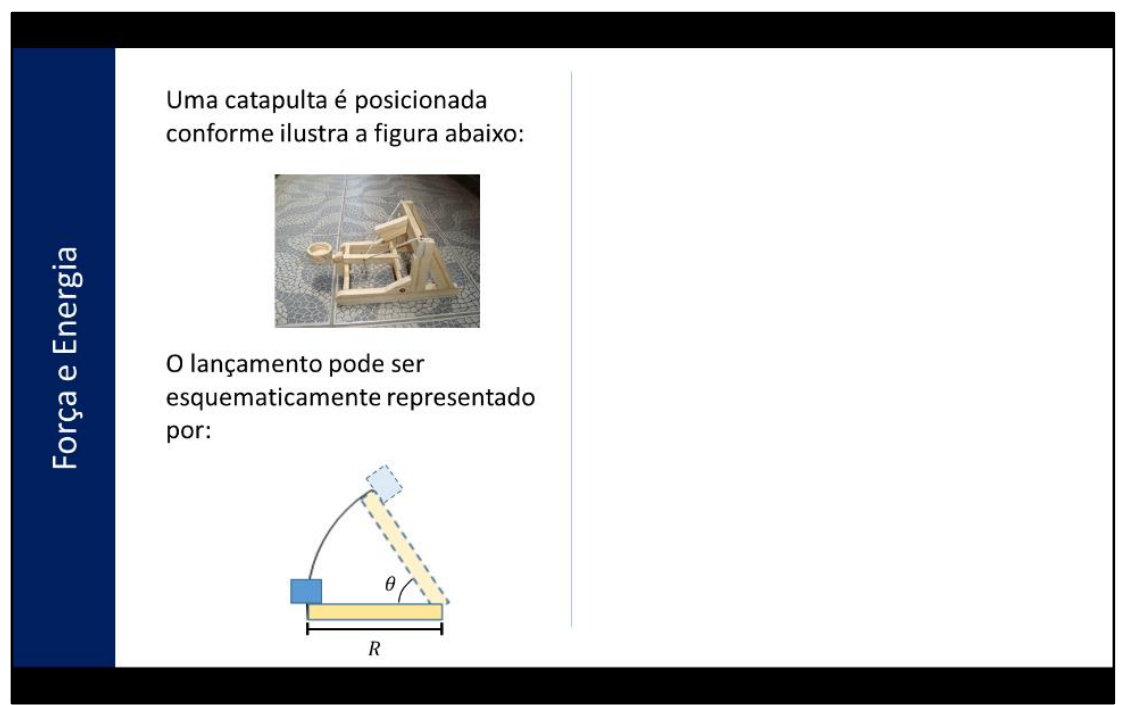

Fonte: Os autores

Na S1, Vânia tenta indicar ao professor, entre as figuras do slide, em qual ela apresenta dúvidas. O professor demora até encontrar a figura a qual a aluna faz referência, mas se mostra disponível até encontrá-la. Nesse contexto, entende-se que a aula se configura como uma situação em que os alunos se sentem confortáveis o suficiente para sobrepor sua fala a do professor, além de indicar a ele questões que não estavam claras até o momento. O professor se mostra aberto às questões colocadas pelos alunos na maior parte do tempo da aula, buscando responder às suas dúvidas.

Cajal (2001) observou que ações rotineiras por parte das professoras foco de sua análise dizem respeito ao atendimento aos alunos, ao serem solicitadas. Esse procedimento, entretanto, poderia ocorrer por meio de ações não verbais ou por meio da fala. Na situação aqui analisada, o professor costuma atender aos alunos através da fala e, também, ratificandoos por meio de ações não verbais (olhar diretamente para cada aluno enquanto fala, aproximarse fisicamente do aluno). Considera-se que tais ações, embora possam parecer sutis, em conjunto, conferem segurança aos alunos para alongar as interações. Esta análise difere do estudo realizado por Cajal (2001), pois o professor é solicitado apenas uma vez durante o recorte selecionado. Percebe-se, no entanto, que a aula transcorre com um padrão de atendimentos, mesclando os procedimentos relatados pela autora.

Na aula observada, Marcela é a aluna mais distante do grupo, acomodada na extremidade oposta da sala e parecendo, em muitos momentos, não estar ratificando o professor ao olhar e mexer constantemente no telefone celular ou tomar chimarrão. Nesta situação, Bauman (2005, p. 33) afirma que os "telefones celulares são suficientes para exibir indiferença em relação à rua em que caminhamos, não mais precisando de uma etiqueta 
rebuscada. Ligados ao celular, desligamo-nos da vida”. O comportamento social (predominantemente não verbal) de Marcela nesta aula, em específico, não difere de outros comportamentos similares presentes na cultura local no contexto institucional sob análise; entretanto, como mencionado na seção anterior, a aluna optou conscientemente, nessa aula, por esse padrão, com a justificativa de "não embaralhar as ideias" durante a realização da prova subsequente. Dessa forma, a única participação de Marcela relativa ao conteúdo tratado é configurada como uma fala iniciada por ela, ao iniciar seu turno de fala após uma pausa dos falantes anteriores, como reflete a Situação 2 (S2).

Situação 2:

21 Professor: ((questiona como se sabe o ângulo de lançamento de um objeto))

22 (o:02 de silêncio)

23 Marcos: [(fala não compreendida)]

24 Marcela: Professor... se tu tiver os: se tu tiver ali embaixo o número da: do primeiro s2, tu consegue fazer o ângulo-

25 Professor: esse do meio aqui? ((aponta, aproximando-se do slide))

26 Marcela: é

27 Professor: e desse? ((indica outro desenho))

28 Marcela: -<êh > [por que não?]

29 Professor: [Hum:] não: só se fosse (um retângulo). Não é retângulo, certo?

30 Marcela: <então eu não sei>

31 (o:08 de silêncio)

32 ((O professor aproxima-se de Marcos))

A fala de Marcos na linha 23 é baixa, por isso, acredita-se que Marcela não o tenha escutado, aproveitando a pausa para iniciar seu turno de fala. O professor atende seu chamado; entretanto, parece não ter respondido à sua questão, encerrando o diálogo. Em função disso, Marcela pode ter sentido-se deslocada, restringindo-se ao silêncio para preservação de sua face, já que não estava inserida plenamente no contexto daquela aula, nem fisicamente (sentou-se afastada dos demais) e nem manifestando, em geral, outras formas de pertencimento (verbal ou visual).

Nesta aula, a fala revelada pela aluna, ao dizer < então não sei>, bem como o posterior silêncio coletivo (de oito segundos), ocorre apenas uma vez; entretanto, são frequentes em aulas de Ciências Exatas, uma vez que os alunos muitas vezes sentem-se envergonhados por não compreender e, ao invés de seguir adiante a interação, silenciam-se. Para Pedrosa (2000, p. 149), “a elaboração de perguntas é um processo essencial para o desenvolvimento do raciocínio crítico e do pensamento criativo, o modo de perguntar constituirá, assim, um instrumento fundamental no processo de ensino e aprendizagem”. Dessa maneira, ao elaborar um questionamento, a aluna demostra, para além de estar ratificando o professor, a tentativa de um processo crítico de construção sobre o conteúdo em questão. 
Também observaram-se cadeias de trocas de turnos de fala entre professor e alunos, que Silva e Amaral (2017), em um estudo realizado em uma aula de Química, apontam como a existência de um padrão, que parte de uma iniciação (I) por alguma das partes, tornando possível o prosseguimento $(\mathrm{P})$ da fala do aluno ou o professor fornecendo um feedback $(\mathrm{F})$ para que o aluno elabore ou reelabore seu raciocínio. Na aula objeto, percebeu-se que tais cadeias iniciavam por uma fala (em geral, questionamentos) do professor, alongando-se a partir das falas e dúvidas dos alunos. Assim, percebeu-se esta sequência como uma forma de incentivo à participação dos alunos em aula, contando suas experiências, ao invés dos monólogos típicos de uma aula meramente expositiva. Na aula observada, a cadeia ocorre com maior frequência entre o professor e Marcos, como ilustramos na Situação 3.

Situação 3:

33 ((Comentário do transcritor: falando sobre a aula anterior, em que foram construídas as catapultas))

34 Marcos: a gente pegou... tinha um palito na [frente e daí se tinha que puxar forte]-

35 Professor: ah:: tá:: ótimo ((concordando com a cabeça)) melhor ainda. (Mas a: o final que era assim) ((movimenta os braços, formando um ângulo)) ou vocês ((movimenta o corpo para mudar o ângulo dos braços)) [pra baixo]

36 Marcos: podia colocar assim ou assim:: ((gesticula com as mãos para exemplificar))... com a batida ela [podia terminar assim:: dependia de como tu queria]

37 Professor: [ah: bom] ótimo $\uparrow$ então- e você sabe quando o lançamento vai ser... ((sinaliza com as mãos)) ajustado no ponto (fala não compreendida)

38 Marcos: (fala não compreendida) < pega o ângulo aqui > ((gesticula com as mãos)) (fala não compreendida).

Na S3, Marcos relata a vivência da aula anterior, em que os alunos construíram catapultas com o auxílio do aluno-monitor do componente curricular, e, por meio do resgate da prática, busca explicar seu entendimento sobre o conteúdo. O professor, percebendo aplicações incorretas, consegue incentivar Marcos a prosseguir sua fala, posteriormente com o aluno indo até o quadro para explicar seu ponto de vista sobre o assunto, a partir de seu exemplo.

O professor, mesmo sabendo que o aluno não estava aplicando os conceitos de forma adequada, não disse que ele estava errado, preferindo incentivá-lo a expor suas percepções, para assim ganhar elementos que o auxiliassem a perceber em que ponto o aluno estava errando e, com isso, problematizar a questão. Esse processo é fundamental no exercício da docência, pela intenção do professor em marcar positivamente os alunos, explicando os motivos da ocorrência do fenômeno suceder de determinada forma e não de outra.

O posicionamento de problematizar a partir dos erros dos alunos, bem como a postura do professor ao planejar a abordagem dos conteúdos (mesmo a partir de uma organização curricular de base tradicional), encaixam-se em atitudes esperadas dos docentes na 
contemporaneidade, como descreve Fernández (2000). Nesse sentido, algo interessante de destacar é que o professor não corrige os alunos, apontando que estejam errados, mas oferece opções e argumentos para que eles repensem as possibilidades, até que percebam os melhores caminhos a serem tomados, como se observa na Situação 4.

Situação 4:

39 Professor: então como você calcula esse ângulo? ((cruza os braços e se afasta de Marcos))

40 ((Marcos aproxima o rosto do quadro, próximo a algo escrito e circulado, olha para o professor sorrindo e fazendo sinal de positivo com a mão))

41 ((o professor se aproxima novamente para ler))

42 Professor: hh hh

43 Marcos: não é

44 Professor: (fala não compreendida) ((Marcos entrega o pincel para o professor)) ó ele vem, lançou aqui ((desenha no quadro)) é esse [ângulo aqui] ((indica o ângulo no próprio desenho e olha para os demais alunos))

45 Marcos: [ah:] é esse aqui ((indica no desenho anterior))

46Professor: aham... então repara que se ele tivesse aqui ó, ele teria que ser ah: integral, porque: o projétil ele sai em linha reta, certo? Então conforme eu vou jogando um pouco mais pra baixo, esse ângulo vai mais pra cima, então o ângulo de lançamento, esse teta aqui, é basicamente o mesmo...que esse daqui ó

47 ((Marcos olha para os desenhos do professor, coloca as mãos na cintura))

48 Marcos: hh eu vou me sentar depois dessa, tô: chocado.

$\mathrm{Na}$ S4, ressalta-se a função construtiva de deixar o aluno perceber a melhor forma de resolver as questões, sendo do professor o papel de oferecer auxílio e os meios que direcionem nesse sentido. Dessa forma, Marcos demostra sua compreensão do conteúdo e, para isso, o professor não precisou corrigir o aluno, dizendo-lhe que estava errado, mas mostrando as possibilidades mais adequadas. Para tanto, tornou possível que os alunos expusessem seus entendimentos sobre o conteúdo. Nesse sentido, Pedrosa (200o) ressalta que o processo fundamentalmente interativo em que se constitui a aprendizagem deixa ao professor o papel de criar as condições necessárias para que esse processo proporcione a construção de saberes, atuando como um intermediário criativo nesse percurso.

Por fim, percebeu-se que o professor tem, em geral, papel incentivador para a participação dos alunos em aula, utilizando situações em que são aplicados os conceitos estudados, criando um ambiente propício para a sua problematização, evidenciando, assim, o papel explicitamente argumentativo que a linguagem verbal e os demais recursos utilizados em sala de aula podem exercer na construção do conhecimento, pois a fala de Marcos, na linha 48, evidencia justamente esse processo, ao afirmar estar "chocado" quando efetivamente conseguiu compreender o que estava sendo discutido. 


\section{Considerações finais}

Buscou-se, neste texto, analisar a interação no contexto de uma aula do componente de graduação Física Geral I, integrante de um curso presencial de formação de professores de Física em uma instituição pública de ensino superior no sul do Brasil. Para tanto, optou-se por um referencial teórico e metodológico que desse conta de trazer uma compreensão situada daquele espaço, marcado tanto pela dinamicidade quanto pela complexidade inerentes a uma contemporaneidade permeada por identidades vistas como líquidas, movediças, sempre dispostas a serem recriadas, seja em momentos de interação mais corriqueiros, seja nos mais institucionalizados. Inclusive, assumindo que há fluidez também na tentativa de categorizar, infrutiferamente, quando começa e quando termina cada estrutura de participação durante as diversas interações cotidianas, incluindo as produzidas na sala de aula, pois ora há manutenção dos papéis institucionais, hora eles são subvertidos ou rejeitados pelos participantes.

No campo empírico, pesquisas dessa natureza visam contribuir para a tomada de decisão, que é coletiva, mas também individual, por parte dos atores sociais, em lidar e conformar os momentos de interação nos contextos de ensino e de aprendizagem, pois ainda que há bastante tempo se anunciem rupturas e necessárias mudanças na Educação, persistem muitos elementos engessados institucionalmente, tais como a própria organização e seleção curriculares, a distribuição dos tempos pedagógicos, o processo avaliativo dominante, etc. No campo teórico, um olhar minucioso para os momentos de sala de aula pode contribuir para que os processos reflexivos frente às situações mais corriqueiras possam ser problematizados em níveis mais profundos; gerando, assim, a possibilidade de mudanças que não partam necessariamente de decisões institucionais mais complexas, mas de cada ator social, em seus alinhamentos verbais e não verbais, frente aos demais, no âmbito de suas interações diárias.

Como indicativo de pesquisas futuras, é necessário que os pesquisadores interessados nas temáticas aqui mobilizadas busquem atentar, de forma mais detalhada, sobre os processos de silenciamentos produzidos durante as aulas, a relação entre frequência discente e os resultados dos processos avaliativos empreendidos, bem como na própria natureza do processo avaliativo adotado. Indubitavelmente, todas essas questões se fazem urgentes na investigação a respeito do ensino-aprendizagem na Educação Superior e merecem nossa atenção no campo investigativo.

\section{Referências}

ATAÍDE, M. C. E. S. SILVA, B. V. C. As Metodologias de Ensino de Ciências: contribuições da experimentação e da história e filosofia da Ciência. Holos. Ano 27, v.4. 2011. 
BAIÃO, J. C. Enquadres e Alinhamentos na Interação entre Crianças em uma Partida de "Jogo da Memória”: a co-construção de identidades de gênero no contexto escolar. In: PEREIRA, M. G. D.; BASTOS, C. R. P.; PEREIRA, T. C. (org.). Discursos Socioculturais em Interação: interfaces entre a narrativa, a conversação e a argumentação: navegando nos contextos da escola, saúde, empresa, mídia, política e migração. Rio de Janeiro: Gramond, 2009.

BORTONI-RICARDO, S.M. 2008. O professor pesquisador: introdução à pesquisa qualitativa. São Paulo: Parábola. 135p.

BAUMAN, Z. Identidade: entrevista a Benedetto Vecchi. Rio de Janeiro: Jorge Zahar Ed., 2005 .

CAJAL, I. B. A Interação em Sala de Aula: como o professor reage às falas iniciadas pelos alunos? In: COX, M. I. P.; ASSIS-PETERSON, A. A. (orgs.). Cenas de Sala de Aula. Campinas, SP: Mercado das Letras, 2001.

CHAHUÁN-JIMÉNEZ, K. Evaluación cualitativa y gestión del conocimiento. Educación y Educadores, v. 12, n. 3, p. 179-195, dez. 2009.

ERICKSON, F.; SHULTZ, J. "O quando" de um contexto: questões e métodos na análise da competência social. In: RIBEIRO, B. T.; GARCEZ, P. M. (org.). Sociolinguística Interacional. 2 ed. São Paulo: Edições Loyola, 2013. p. 215-234.

FERNÁNDEZ, J. T. El Docente Innovador. In: TORRE, S.; BARRIOS, O (coords.). Estrategias didácticas e inovadoras: Recursos para la formación y el cambio. Barcelona: Octaedro, 2000.

GABBIANI, B. Escuela, lenguaje y poder. Montevidéu: Universidad de la República, 2000. GIL FLORES, J., DE BESA GUTIÉRREZ, M. y GARZÓN UMERENKOVA, A. ¿Por qué procrastina el alumnado universitario? Análisis de motivos y caracterización del alumnado con diferentes tipos de motivaciones. Revista de Investigación Educativa, v. 38, n. 1, p. 183-200, 2020. Disponível em: http://dx.doi.org/10.6018/rie.344781. Acesso em: 06 mai. 2220.

GOFFMAN, E. Ritual de Interação: ensaios sobre o comportamento face a face. Petrópolis, RJ: Vozes, 2011.

KEBRAT-ORECCHIONI, C. Análise da conversação: princípios e métodos. São Paulo: Parábola, 2006.

KUHN, T. S. A Estrutura das Revoluções Científicas. São Paulo: Editora Perspectiva S. A, 1998.

LEE, C. Language for Learning Mathematics. New York, NY: Two Penn Plaza, 2006.

LODER, L. L. O Modelo Jefferson de Transcrição: convenções e debates. In: LODER, L. L.; JUNG, N. M. Fala-em-Interação Social: introdução à análise da conversa etnometodológica. Campinas, SP: Mercado das Letras, 2008. p.127-162. 
MORENO, L. A.; CÓLON, A. O. Estratégias Metodológicas para el desarrollo de las prácticas de Enseñanza em la Docencia Universitária. Revista de Medios y Educación, enero, n. 022, p. 41-49, 2004.

PEDrosA, M. H. A Comunicação na Sala de Aula: as perguntas como elementos estruturadores da interacção didáctica. In: MONTEIRO, C.; TAVARES, F.; ALMIRO, J.; PONTE, J. P.; MATOS, J. M.; MENEZES, L. Interacções na aula de Matemática. Viseu, 2000, p. 149-162.

PERNAMBUCO, M.M.C. Quando a troca se estabelece: a relação dialógica. In: PONTUSCHKA, N.(org.). Ousadia no diálogo: interdisciplinaridade na escola pública. São Paulo: Edições Loyola, p. 19-36, 1993a.

PILETTI, C. Didática Geral. São Paulo: Ática, 2004.

PIMENTA, S. G. Formação de Professores - Saberes da Docência e Identidade do Professor. Revista da Faculdade de Educação, São Paulo, v. 22, n. 2, p.72-88, jul./dez. 1996.

RECUERO, R. A conversação em rede: comunicação mediada por computador e redes sociais na Internet. Porto Alegre: Sulinas, 2012.

RODRIGUES, C.; MENEZES, L.; PONTE, J. P. Práticas de Discussão em Sala de Aula de Matemática: os casos de dois professores. Bolema, Rio Claro, SP, v. 32, n. 61, p. 398418, ago. 2018.

SALVAT, B. Aprendizajes, conexiones y artefactos: la producción colaborativa del conocimiento. Barcelona: Gedisa, 2008.

SANTOS. B. S. Um Discurso sobre as Ciências. São Paulo: Cortez, 2008.

SAVIANI, D. Escola e democracia: teorias da educação, curvatura da vara, onze teses sobre educação e política. Campinas, SP: Autores Associados, 1999.

SILVA, J. C. S.; AMARAL, E. M. R. Uma Análise de Estratégias Didáticas e Padrões de Interação Presentes em Aulas sobre Equilíbrio Químico. Revista Brasileira de Pesquisa em Educação em Ciências, v. 17, n. 3, p. 985-1009, dez. 2017.

SILVA, G. S. F. E VILLANI, A. Grupos de aprendizagem nas aulas de Física: as interações entre professor e alunos. Ciência \& Educação, v.15, n.1, p. 21-46, 2009.

TINTO, V. Through the Eyes of Students. Journal of College Student Retention: Research, Theory \& Practice, v. O, p. 1-16, 2015.

UNIVERSIDADE FEDERAL DO PAMPA. Projeto Pedagógico de Curso: Licenciatura em Física. Bagé, RS, 2014.

\section{Biografia Resumida}

Valesca Brasil Irala: professora associada, atuando no Mestrado em Ensino (PPGMAE) da Universidade Federal do Pampa ISSN 2526-2882 
(UNIPAMPA). Mestre e doutora em Letras (Linguística Aplicada), pela Universidade Católica de Pelotas (UCPel), com Pós-doutorado na Facultad de Humanidades y Ciencias de la Educación, na Universidad de la República (Uruguai). Líder do Grupo de Pesquisa sobre Aprendizagens, Metodologias e Avaliação (GAMA), registrado no Diretório de Grupos de Pesquisa do CNPq. Seus atuais interesses de pesquisa são: avaliação no ensino superior, engajamento discente, retenção e evasão no ensino superior e tecnologias educacionais.

Lattes: http://lattes.cnpq.br/7316864301240506

Contato: valescairala@unipampa.edu.br

Liziane Padilha Mena: licenciada em Ciências da Natureza pela Universidade Federal do Pampa (UNIPAMPA). Discente do Mestrado Acadêmico em Ensino (PPGMAE) e pesquisadora no Grupo de Pesquisa sobre Aprendizagens, Metodologias e Avaliação (GAMA), registrado no Diretório de Grupos de Pesquisa do CNPq. Seus atuais interesses de pesquisa são: avaliação no ensino superior, através do uso de rubricas avaliativas.

Lattes: http://lattes.cnpq.br/6451009185605231

Contato: lizianemena.aluno@unipampa.edu.br

Rafael Kobata Kimura: professor adjunto A na Universidade Federal do Pampa (UNIPAMPA), atuando em cursos de graduação em engenharias e licenciaturas. Possui mestrado e doutorado em Ciências (Programa de Astronomia), pelo Instituto de Astronomia, Geofísica e Ciências Atmosféricas. Também, pós-doutorado pela Escola de Artes, Ciências e Humanidades da Universidade de São Paulo (EACH-USP), na área de Ensino de Ciências. Entre seus atuais interesses de pesquisa estão a divulgação científica, especialmente através de Planetários e ensino de astronomia em ambientes formais e não formais (via projetos de extensão universitária).

Lattes: http://lattes.cnpq.br/5223309157171934

Contato: rafael.k.kimura@gmail.com 